\title{
Cross Fertilization Between Museums and Schools, Science and Art, History and Multimedia
}

\author{
Lidia Falomo Bernarduzzi • Gabriele Albanesi
}

Received: 1 June 2014/Accepted: 10 January 2015/Published online: 10 February 2015

(C) The Author(s) 2015. This article is published with open access at Springerlink.com

\begin{abstract}
In 2011 Pavia University celebrated its 650th birthday. This provided the opportunity to propose the Neverland project whose purpose was to overcome the division between formal and informal science education. A number of classes (various age groups) from a group of schools in the province of Pavia took part in the project. The University Museums (Physics, Medicine, Mineralogy, Natural History, Botanic Garden) and Laboratories joined forces. Each class adopted a famous Pavia scientist of the past (including Volta, Scarpa, Scopoli, Taramelli and Golgi), visited the corresponding museum and undertook specific laboratory activities. Once back at school, the information gathered was related to the history of modern figurative art focusing on the role of analogical inference, often relevant both in scientific and artistic innovation. Participatory videos and multimedia were produced. The Neverland project draws on the past work of the History of Physics Group starting in the 1980s and 1990s which aimed to preserve, restore and explain through 3D multimedia old physics instruments. This work led to the foundation of the University (Science) Museum System. Interactive exhibitions were dedicated to Volta (1999), Einstein (an international project run in 2005 in conjunction with Berlin and Jerusalem and with contributions from Oldenburg and Pisa), Galileo (2009), and the history of the energy conservation principle (2011). In all of them, high school students were trained to play the role of "explainers", carrying out a series of historical experiments with younger pupils, classmates, and the general public. The various activities were coordinated by university students. The youngest participants were encouraged to develop forms of "artistic" expression based on the feelings and ideas experienced in their exposure to scientific activities.
\end{abstract}

\footnotetext{
L. Falomo Bernarduzzi ( $\square)$

Department of Physics, University of Pavia, Pavia, Italy

e-mail: Lidia.FalomoBernarduzzi@unipv.it
}

G. Albanesi

Via Breventano 69, Pavia, ITALY

e-mail: albangab@alice.it 
Keywords Formal/informal science education - Formal/informal images $\cdot$ History of science $\cdot$ History of art · Multimedia

\section{The University of Pavia's Museum System}

The University of Pavia is very old: it was founded by Charles IV in 1361. During the fifteenth century its prestige grew-a number of colleges were established and the current main site was used for lectures. In the sixteenth and seventeenth centuries the university experienced a period of crisis, but nevertheless saw the establishment of the city's two most important colleges. Such illustrious persons as Gerolamo Cardano (1501-1576) and Gaspare Aselli (1581-1626) were teaching there at the time. In the eighteenth century the reforms of Empress Maria Theresa and Emperor Joseph II of Austria made the University one of the most famous in Europe. Many university collections were established in those years: the Museum of Natural History was established in 1771 under Lazzaro Spallanzani (1729-1799); 1771 also saw the creation of the Physics Laboratory under Carlo Barletti (1735-1800), who was succeeded by Alessandro Volta (1745-1827); the Botanic Garden was founded in 1773, and expanded under Giovanni Antonio Scopoli (1723-1788); the medical collections were established in the 1780s, and Antonio Scarpa (1752-1832) became curator of the Anatomy Museum, which housed the normal and pathological human anatomy and comparative anatomy collections. The University laboratories and museums became places of teaching and for disseminating scientific knowledge. Professors were required to perform public experiments, and hold demonstration lessons once or twice a week. The best students assisted and worked with their professors in their research activities. The collections grew as a result of a dense network of relations that extended throughout Europe. The university laboratories, especially in physics, became nodes in a network that stretched to all grammar schools in the province, and saw the presence of the most important instruments in the various branches of physics in each school.

In 1796 Napoleon defeated the Piedmontese and the Austrians, and conquered Lombardy. This led to a number of rapid political changes: the first Cisalpine Republic, the Austro-Russian reaction, the second Cisalpine Republic, the Napoleonic Italian Republic, the Kingdom of Italy, the return of the no longer "enlightened" Austrians. Despite the political, institutional and economic difficulties, new laboratories were founded in the first decade of the nineteenth century (Hydrometry, Geodesy and Architecture), others in the middle of the century (Technology, Science of the Construction of Machines). They were then transferred to Milan, where a Higher Technical Institute for engineers was established.

In 1885 the University expanded by acquiring Botta Palace, at the time the most sumptuous private house in Pavia. The Institute of Pathology was relocated there. The institute became famous under Camillo Golgi (1843-1926), who made fundamental contributions to medicine and biology and received the Nobel Prize in 1906. 
In the 1930s, the old research laboratories were turned into museums (e.g. the History of Pavia University Museum was founded in 1936) and, following a refurbishment of the University buildings, new collections were founded in the new institutes of Anatomy, Physics, Chemistry and Histology.

The most recent re-organisation (Bevilacqua et al. 2003) began in the 1980s. The Museum of Mineralogy, whose oldest specimens date back to Lazzaro Spallanzani, was transferred to its new home. The same happened to the Mathematics collection. Finally, in the early 2000s the Museum of Electrical Technology was founded.

The university science museums are today working to revive the strong educative function that characterized their origins. This means actively engaging all the various visitors both through the use of the history of science and modern university laboratories, which are often housed in the same buildings as the museums. They also want to expand their role as a key node in the network of schools extending throughout the region, through formal and informal educational activities and by collecting data on the historical collections held in the schools in order to enhance them.

\section{Formal/Informal}

Formal/Non formal/Informal Education

The literature discussing the distinction between formal education and non-formal and informal education stretches back a number of years. The distinction can be seen in the generic division between formal/informal education, and even in this dichotomy there are many ambiguities (Hodkinson et al. 2003). We refer in particular to Eshach's definition of the three types of learning (Eshach 2007, p.174) and show how they can be integrated into a common framework through a close partnership between formal educational and non-formal cultural institutions in the Pavia area working on a single project. This has, as described below, several implications and effects also on the level of informality (web, augmented reality, interpersonal relationships). In addition to the visit, and the workshop, and the use of the Museum's collections as an opportunity to "supplement", extend or explore an individual school subject (Kisiel 2005), schools began to plan their educational activities in conjunction with museums. The objectives and content of the projects were based on the nature of each museum as well as the curriculum pathways of individual school subjects.

\section{Formal/Non formal/Informal Learning}

Rigorous cognitivism and the logic of deductive/inductive learning forces us to pay more attention to the mechanisms of cognition than to the situation in which it takes place. We must, therefore, consider those attitudes and theories that pay or have paid more attention, not only to the mechanisms of thought, but also the social context, and the nature of the cultural offerings, and conditionings. We refer, for example, to the processes of assimilation and accommodation (Piaget and avec la 
collaboration de Garcia 1971), and mediation and social interaction (Vygotskji 1990), as well as to recent research on multiple intelligences (Gardner 1983) or to the pluridimensionality of mental life (Bruner 1986, 1996). In this respect, we can think of the learning process as one of continuous, up-to-date exchange between external stimuli and their internal encoding, even in the presence of digital tools (Jonassen et al. 2008). It is an ongoing process involving not only logic/deduction, selection and cataloguing, but also other forms of thinking, different mental, behavioural and psychological processes, attitudes, as well as sensations, feelings and impulses. It is therefore a subtle, continuous exchange that produces similarities, comparisons, associations and evocations, metaphors and symbols, and forms of analogical thinking. The science museum becomes a place with collections of objects evoking stories and biographies, theories and abstractions, people and problems, initially within the clearly marked boundaries of a specific scientific path, but soon spreading and creating associations, triggering other routes, tailored to the memory of each person, to the stories heard (in the case of schoolchildren), to areas not yet defined in his/her personal life experience. One moves away from the subject. Associations between different dimensions, between technology and humanism, between science and art are activated.

Einstein (1879-1955) and Picasso (1881-1973), for example, did not cross paths, and the theory of relativity never came into contact with the contemporary concerns of Cubism. Indeed, Einstein himself said, in a letter replying to Paul Laporte (who, before its publication, had sent him his essay entitled Cubism and the Theory of Relativity written in 1945): "This new artistic "language" has nothing in common with the Theory of Relativity". However, a few lines earlier in that same letter he stated:

If I disregard the practical value of a science I do see a similarity between the scientific and the artistic activity. Both attempt to assemble from parts a whole which by itself is indistinct-(ein an sich unuebersichtliches Ganzes) in such a way that the resulting order creates distinctness and clarity. The distinctness and clarity thus achieved gives us a satisfaction of a high order. This occurs both in science and in art. In science, the principle of order which creates units is achieved through logical connection while, in art, the principle of order is anchored in the unconscious... (Laporte 1966, p. 246).

We would like to think that Einstein and Picasso met involuntarily "at an analogical level" or even just "at a metaphorical one".

So the connection between Art and Science has its rationale, its raison d'être lies in the value of learning "by analogy." This encounter can produce (and the final exhibition of the "Neverland" project is concrete proof of this) operations, ideas, objects, drawings/paintings. This "doing" involves "understanding" the reasons (figures in science and scientific subjects, scientific theories, documents kept in the Museum) in order to subsequently "translate" them into images, in a "modular" or "multiple" behaviour of knowledge engaging different intelligences, and making use of various production techniques for the same topic.

In the context of the museum, this "understanding by doing" (De Bartolomeis 1990) is initiated and developed through the workshop. The scientific workshops conducted within various contexts of the University of Pavia's Museum System 
perform this function on several levels: experimenting synergically ${ }^{1}$ together (and even synesthetically to some extent, if we consider the willingness of younger children to explore their experiences with the involuntary and tender help of the five senses: the smell of the museum, its colours, the "slipperiness" of some equipment, the sting of the electric shock felt by children, etc.), in a controlled manner, using deductive logic and consistent explanations, but which leave each young person the freedom to "explore science" using "every one" of his/her intelligences. In the context of the last completed project— "Neverland" — we also ran a participatory video workshop. Under the expert guidance of a filmmaker, children from some sample classes turned into actors, directors and sound technicians, and proceeded to explore the museum with the use of camcorders.

In these short professionally edited and produced videos, ${ }^{2}$ the metaphor of analogical exploration of the museum was refined further, and took on the form and style of an exchange with the museum, translated into a visual story. The videos revealed not only the rigour of scientific narrative, and its faithful reproduction, but also narrative strategies, aptitudes and opinions. The term participatory video accurately indicates the collective nature of the experience, which does not detract from the scientific quality of the narration, yet at the same time gives it an emotional sense of discovery, of wonder. These analogical paths are rich in sensitivities and emotions, the same emotions experienced when performing a scientific experiment, a sense of novelty and at the same time of the verifiability of a hypothesis.

\section{Formal/Informal Images}

In both visual art and science the analogy is between reality and its representation. Museums possess documents, instruments, objects and images in general about reality investigated from a scientific viewpoint. In our case they are the museums of physics, medicine, botany, and earth sciences. Both art and science use two types of images, a "realistic" kind (as we perceive things), and another that is mental, conceptual in nature (schemas, models, formulas). Science also uses technical tools-microscopes, telescopes, computers, sensors-thus expanding the perception of reality. The mental and conceptual processing of the observed world is translated into schemas, taxonomies, formulas, graphs, models, and generally into "signs of thought" by introducing into research elements and marks of visual grammar, the same grammar that is used in the visual arts. This "thinking in pictures" must also make use of the same visual rules. ${ }^{3}$

\footnotetext{
1 All the "players" - students, teachers, museum staff and those involved in the university workshopsare engaged in this dialogue through interaction with the artefacts (interactive exhibits, new technology, historical and natural specimens) and situations (sharing, co-operating, negotiating, verbalising intuitions, doubts, asking them to reflect, to try out etc.).

2 A number of participatory videos produced by the classes can be viewed at: http://musei.unipv.it/3_ didattica/didattica.html.

${ }^{3}$ We know that the world that we see before us whenever we open our eyes - the colours, shapes, movements and expressive qualities of objects-is not a mere copy or mirror of the physical world around us. It is also the result of the construction of the visual system which, through a complex chain of operations and processes, transforms and organises the incoming sensory messages. The eye and related neurophysiological mechanisms are only the beginning of this organisational process. It is at this level of
} 
The observations that arise from seeing the world directly or indirectly are put together and integrated with abstract or informal types of image.

In particular, formal (figurative and realistic), informal (gestural and material) and abstract (geometric and compositional) are typical categories used in visual art to represent the physical (reinterpretation of reality) or mental (feelings, attitudes, affections).

We can imagine this as the "poetic journey" that the artist and the scientist undertake hand in hand as they set off on their journey. Both open their eyes to the spectacle of the world, they are dazzled, both begin to describe it, each with her or his own language: the artist begins to investigate nature, configures shapes and relationships, brings into focus shapes and contrasts and then begins to turn what she or he sees into a visual representation, using the elements of visual language (colour, light, point, line, surface, etc.). Soon she or he moves away from realistic narration, she or he moves in different directions, she or he prefers abstract shapes, chooses geometric figures, reduces them to their essence, frames them, looks for compositions, makes (informal) choices of pure form, then imitates nature, its indistinct surfaces, humus and matter without definitions or boundaries (these are the choices of material, sign and informal art). The scientist too investigates nature. She or he, in turn, is dazzled, she or he searches for origins and causes, senses the presence of laws and dependencies, inferences and relationships, she or he hypothesizes changes, translates her or his perceptions into hypotheses using, for example, geometry, mathematics and formal logic. She or he deduces models, laws, seeks confirmation, transforming her or his initial visual perceptions into completed schemas, which she or he is able to represent fully in her or his mind and to rewrite on a blackboard. These schemas/graphs/formulas are "abstract" translations of her or his deductions i.e. non-realistic forms which nevertheless still represent reality.

In our projects with schools we have often dealt with this interplay between different forms, between realistic and abstract/informal re-interpretations of reality, of the world, of nature, rediscovered in art galleries and science museums. Indeed, young children have, if properly educated and guided, an incredible creative and expressive capacity, but also, in relation to the investigation and credibility of events, one capable of distinguishing between reality and image, between the real world and imagination. Children do not easily lose sight of the distinction between real and virtual, they have no difficulty in playing with analogies (Falomo Bernarduzzi et al. 2012) as well as with scientifically correct definitions, which they keep in their memories. If, for example, during a visit to the Museum of Mineralogy a child is shown images of thin sections of minerals seen under the polarized light of a microscope, she or he will be able to enthuse about the colours she or he sees in these images better than an adult, and, if she or he possesses the necessary information, be able to translate/re-live the same sensations in other types of images, for example in abstract works of visual art. But she or he will also be able to

Footnote 3 continued

analysis that fundamental, long-running experimental research has accurately formulated the main "rules of vision", with their chromatic, dimensional, formal and physiognomic parameters. Like those of written and spoken language, these rules are summed up by the term "grammar of vision" (Kanizsa 1980). 
"copy" or "reproduce" these images, using visual memory and sensitivity, and produce her or his own personal drawings. She or he will be able to carefully "observe" the surfaces of minerals and, from that informal knowledge, invent, produce, configure realistic images, as we all do when we dreamily look at clouds in the sky. She or he will even be able to draw a cloud "in the manner of Picasso or Kandinsky (1866-1944)".

She or he must, however, learn to observe, for example, the moon in the sky, to dream about, reflect on and rediscover that same and yet different moon in a painting by Van Gogh (1853-1890), look for it again through a telescope, in order to learn to understand it better, to draw it and to surf the seas of Internet, and share the experience with all the world's children. ${ }^{4}$

\section{The Child's Representation of the World}

Meanwhile, we also try to identify and distinguish, in the context of, and alongside informality, two types of images: those that are formed in the mind, as patterns, tracks, models, formulas, which we can more appropriately define as abstract, and those that are drawn directly from our personal visual experience through the mechanism of configuration. Configuration is present in every kind of mental or graphical representation of the outside world, be it formal (figurative, realistic, photographic) or informal (stains, signs without any naturalistic connotation). Configuration allows us to recognize an image, connect it to a schema, classify it, and thus include it among already known images; in the case of unknown signs, informal stains or images of unknown objects, configuration allows us to draw comparisons, make connections, analogies, and, possibly define a new category of image. Configuration helps us to move away from the discomfort of incomprehension (I do not understand what I see...) and tends to allow us to fit a confusing image within a familiar visual category. In this respect, it may be considered linked to the rule of good form cherished by Gestalt psychology. That is why we encourage efforts to identify known forms in unknown informality such as figures in clouds or in stains on walls. This may be an inevitable and automatic activity, which we yield to by virtue of the power of order (Gombrich 1979).

More generally, the distinction between formal, informal and abstract, when reduced to the dimension of images, may be defined as the difference between realistic and non-realistic. It is related to the concept of visual realism. If a realistic image is one that represents reality as we perceive it, it is the result of a consolidated common sense conception which identifies external reality with the images of it produced by our binocular, perspective, photographic vision. According to more traditional developmental psychology, from the age of three all children begin to represent the world using forms of visual realism: this form of representation, which we can define very simply as "formal" is gradually consolidated through the use and increased application of consolidated and repeated interpretational (or conceptual) frames. In this respect, children's drawings can be defined as

\footnotetext{
${ }^{4}$ Teaching paths and drawings of the moon and sun can be found at http://galileolab.wetpaint.com/page/ Come+la+vuoi+la+luna\%3F.
} 
stereotypes. Different types of increasingly sophisticated schemas, over the years, i.e. increasingly defined as "truthful", accumulate, almost as if moving in an obligatory figurative direction, moving inexorably towards a sort of accepted representative realism of adulthood. The ability that children of all ages have to express themselves graphically also through signs (using both visual languagecolour, lines, light, abstract forms etc.- -but also through the synaesthesia of signs from other senses-sounds, tastes, smells...) that are not structured in a realistic sense, suggest that the "realistic path" is not the only, inevitable one, but also the unwitting result of the encounter with the adult culture of which the child is a part from birth. Realistic figurative stereotypes are the result of a form of accommodation (Piaget 1923) to the adult, through which the child obtains immediate gratification and understanding. For the sake of communicative economy other "informal" graphic signs are neglected, this time by the adult (parent, educator, media...), and only emerge in specific contexts, as in our projects.

\section{The Educational Role of Museums-Planning Together with Schools}

The nature of the close partnership between the schools in the Pavia area and Pavia University's museum system requires us to consider the guidelines laid down by the Italian Ministry of Education, Universities and Research (MIUR), particularly the National Guidelines for the curricula of infant schools, primary schools and lower secondary schools (Ministero dell'Istruzione and dell'Università e della Ricerca 2012). They expand the opportunities for collaboration and reinforce the bases of existing projects. These new educational and cultural scenarios set out, in very clear detail, the scope of a "new humanism", placed within a context of increasingly broad and globally interconnected geographical, political and cultural boundaries. Within such a context, the divide between "humanistic culture" and "scientific culture" loses its meaning. Instead, the encounter between science and art, which is developed in context in all our projects, becomes ever more relevant. The distance between "formality" and "informality" in education also tends to shrink. The educational content presented within the context of the Guidelines, at the various school levels, modify the objectives and the very boundaries of the disciplines involved. The Guidelines propose greater interaction between different disciplines and set concrete goals. They call for better-targeted, more clearly defined interdisciplinary project goals, which are open to the social, to exchange with the local community and its cultural agencies. The dimensions of "the local" too are extended towards "the glocal" through the Net and the World Wide Web.

It is, at the same time, an attempt to simplify the normal school "curricula", which are required to set goals, timelines, clear and consistent objectives and assessment methods, all within better selected and more focused content.

In this completely revised educational and cultural dimension, the definition of the curriculum has expanded, while projects with museums acquire more concrete goals, as well as greater educational responsibility.

The Guidelines for pre-school (3-5 years) education structure learning within the confines of the five fields of experience: The self and others, body and movement, 
images, sounds and colours, discourse/conversation and words, knowledge of the world. This is, therefore, a dimension that is not yet divided into disciplines, but which involves different modes and approaches; it is a synergy or "global" interaction of at least three approaches:

The narrative, based on spoken language, description and story-telling; the creative, based specifically on art and its various fields, but also on new media and new languages of communication, which young children encounter as spectators and as actors. A third approach, based specifically on exploring the body, objects and nature through the five senses, comes into contact with the "world". Here, attention is focused especially on the environment, natural phenomena, the world of animals as well as the shape and functioning of the human body.

These three approaches, based on the Guidelines, can be found in our projects for children aged 3-8, offered in different forms for this broad age range, but always interconnected in various ways. During their visits to museums and "places of science" and in the laboratories/workshops they explore through observation and the use of their senses, in general, in playful, emotionally engaging contexts that provide synesthetic stimuli (Vecchiato 2007; Oliverio and Oliverio Ferraris 2005; Singer and Singer 1990; Macchietti 1997; Bruner et al. 1976). Examples include: a visit to Alessandro Volta's study and then to his laboratory, where children observe certain phenomena, such as lightning, simulated through the spark of a Wimshurst electrostatic machine. They are able to perceive the sound of the spark, its smell, and imagine its effects; they are able to feel on their skin the small sparks generated by a Volta electrophorus. They can "taste electricity" (through two tea spoons made of different metals placed on the sides of their tongues), as Volta himself did. In this way, they explore these phenomena through their senses, as has happened to scientists, before instruments were devised to detect, and later, measure them. In the medicine section they can look inside the human body, through wax models, and through 18th and 19th century skeletons and interesting slides under the microscope, such as those prepared by Camillo Golgi. In the Natural History Museum they can compare the human body with those of animals, observing their differing anatomical structures, resulting from different functions and evolution...

Their sensorial experiences, their visual-graphic expressiveness and oral narration skills increase within a general, global (Wallon 1963; Pichon-Rivière 1987) "story of the world", in which the children live and within which they begin to approach science. They ask questions, try to understand what cannot be seen (like scientists), they develop a sense of wonder about what they do not know (again like scientists).

Clearly, visual narration prevails, hence the reliance on "stories" using images, which are produced in school workshops that take place following museum visits. Now begins a journey in which, through learning, images become increasingly important. Later these indicate and turn into "visual models", which will then become an important part of the scientifically-based cognitive process. At these ages, the stories based on the history of science are largely about people and objects in our projects both in the museum and at school. The pieces produced such as artefacts, drawings, videos and stories related to their explorations, maintain an 
imaginary and playful dimension. What can later be narrated, reported and exaggerated to their families becomes important for the children.

This global perspective persists in later years, but is gradually toned down, grows more mature, and becomes more specialised from the age of 8-9, when the narrative, creative and exploratory approaches initially experienced in synergy, differentiate. The context continues to be stories, but this time narrated using specific languages. Again, to quote the Guidelines at the end of primary school (11 years), children should:

Develop a sense of curiosity and ways of looking at the world that encourage them to look for explanations of what they see happening around them. Explore phenomena using a scientific approach. With the help of the teacher, their classmates, on their own, they observe and describe events as they happen, ask questions, on the basis of personal assumptions, devise and carry out simple experiments. Identify similarities and differences in the phenomena, make measurements, record significant data, identify space-time relations. Identify quantitative and qualitative relationships in phenomena, produce graphical representations and drawings of an appropriate level, develop simple models... (Ministero dell'Istruzione and dell'Università e della Ricerca 2012, p. 56).

The guidelines provide indications on the "methods" and "structures" and "representations" and "models" that form the backbone of scientific research and are a prelude to the Guidelines for the Lower Secondary School Curriculum, where Physics, Chemistry, Astronomy, Earth Sciences and Biology are taught for the first time. The attainment goals for the skills to be developed at the end of this level of education (age 14) are the following:

Pupils explore and experiment in the laboratory and outdoors, the most common phenomena as they occur, they imagine and verify the causes; they look for solutions to problems, using the knowledge they have acquired. They develop simple outlines and models of facts and phenomena using, when necessary, appropriate measures and simple formulas... They make connections between the development of science and the development of human history. They develop curiosity and interest in the main problems related to the application of science in scientific and technological developments. (Ministero dell'Istruzione and dell'Università e della Ricerca 2012, p. 58).

Between the ages of 9 and 11 they begin to consolidate the visual models and images that sustain the knowledge they acquire. This thinking in images is reinforced through the use of illustrations, relies on science stories told through videos, films, comics, photographs and cartoons. As they improve their skills of expression (including graphical), pupils use figuration to tell stories of science, to illustrate experiments, to report laboratory work.

From the age of $12 / 13$, the visual models are less tied to the real world and turn into outlines, graphs and diagrams, which pupils learn to draw in order to summarize concepts, science stories and scientific information. These are the analogue pictures that accompany and grow alongside knowledge and concepts acquired through deductive reasoning. They are perceptions, configurations, combinations and inventions of forms, metaphorical associations and similes, identifications between already coded mental patterns and new experiences. This 
dynamic activity nourishes their "visual thinking", it combines concepts and images, consolidates outlines and creates reference models. These models are continually moving away from the initial forms of visual realism, characteristic of earlier developmental stages - they are no longer naturalistic but tend towards abstract and essential forms.

Thanks to these skills, which have now become interdisciplinary in nature, as pupils have mastered different languages through specific areas of research linked to the subject areas, the work proposed in the context of history-science and modern workshops in museums and in the multimedia ones at school become easier and more productive. Pupils are now able to isolate, even before they reach upper secondary school, contexts of research which are defined as scientific activities. They can describe phenomena and timelines, illustrate and record them as they occur, and make logical deductions. The work, reports, and artefacts produced in these age groups still retain all the features of a science story, but are more detailed and presented using various, simultaneously present languages. They include narrated and illustrated biographies and case studies, comparisons between experiments, the search for analogies between different scientific events, the use of sophisticated images taken from the history of art, graphic summaries, maps and graphs, photographic reports, videos that are published online through social media...

At secondary school level, logical deduction, the results of logical reasoning and the definition of theoretical models become more important. The mathematical knowledge that has been gradually acquired paves the way to science education proper. In this age group (15-19 years old) pupils, after participating in historyscience workshops and modern laboratories, often within more general topics (Heering 2000; Bevilacqua et al. 2006; Andreani et al. 2010) become explainers (they present the historical experiments in the exhibition/workshop held at the end of the project to their peers and to the public). They are also able to use, produce and present exhibits and multimedia materials which focus on science stories, debates among scientists, compare different theories ("impossible" dialogues) and historical contexts (Bevilacqua and Falomo Bernarduzzi 2009; Bevilacqua and Bordoni 2005).

Finally, as regards the last age group, university and doctorate science students coordinate the final exhibition/workshop activities, while undergraduates studying on the communications degree course take part in the project by producing multimedia materials.

Each project, recently almost on a yearly basis, is planned jointly with teachers and starts with update days for them on selected history of science and history of art topics. However, teachers are left to decide the most appropriate way to present the topics to their classes. This enables all the participants involved to develop contemporaneously: museum staff (and academics), who provide their skills, but which is, at the same time, enriched by the different interpretations of their collections and histories of science; teachers who acquire new, specific knowledge and, at the same time see their role as mediators between the knowledge in museums and the learning needs of their pupils enhanced and pupils, who see themselves as 
protagonists not only during the various stages of a project, but also in the final presentation of their products or historical experiments.

All participants, including the teachers themselves, learn through direct involvement, "by doing", thus putting into practice that "eclectic approach to the insertion of the HPS in science teaching" outlined by Stinner et al. (2003, p. 624) through an effort that is collective, and therefore reduced for each participant.

\section{The Neverland Project}

The project came about during the 650th anniversary celebrations of the founding of the university. The celebrations provided the opportunity for the very young to discover the university, to grow with it, as well as renew and strengthen their relationship with the city.

Fifteen schools (nursery, primary as well as 1st and 2nd level secondary schools) in the city and province of Pavia took part in the project. More than a thousand

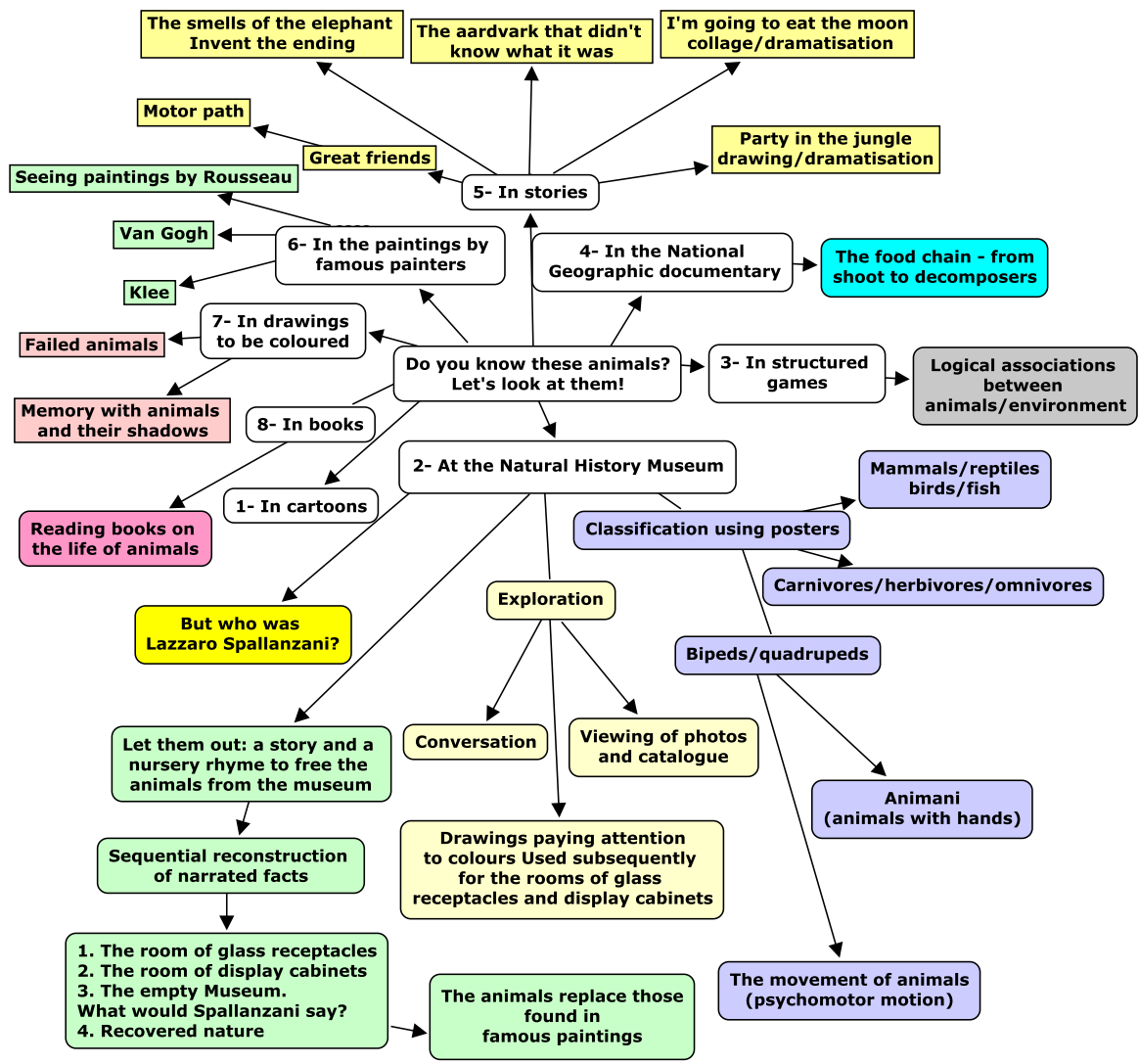

Fig. 1 Map of the activity trails the different classes followed 
pupils and students (thirty-five school classes and a university course) aged 4-22 years old encountered figures in the history of Pavia University, visited its museums, analysed documents, and acquired knowledge. Both logical and analogical paths were adopted in various ways in situated learning occasions. Every participant was guided through science in a rigorous, documented, objective manner, and, at the same time (and this is a little travelled road) was invited to follow parallel paths, which were in some way connected with the original investigation, but which could be "commented" "reconstructed" and "narrated" through tools and techniques based on other forms of knowledge. They included figurative art and painting.

The following are examples of activities carried out by some of the classes participating in the project.

\section{Infant Schools}

In the case of kindergarten children (5 years old), some classes visited the Museum of Natural History.

Each class identified their favourite trails (Fig. 1). The kids especially enjoyed imagining being able to free the animals in the museum and, as in a fairy tale, magically make them come alive in the paintings of famous painters (Fig. 2): Henri Rousseau (1844-1910), Paul Klee (1879-1940), Vincent Van Gogh.

The idea of freeing the animals from their cold display cases was also taken up in the participatory video (Fig. 3): each child, like a little explorer in the darkness of the museum, equipped with a torch to which was attached a mini camcorder, chose an animal, freed it and observed it.
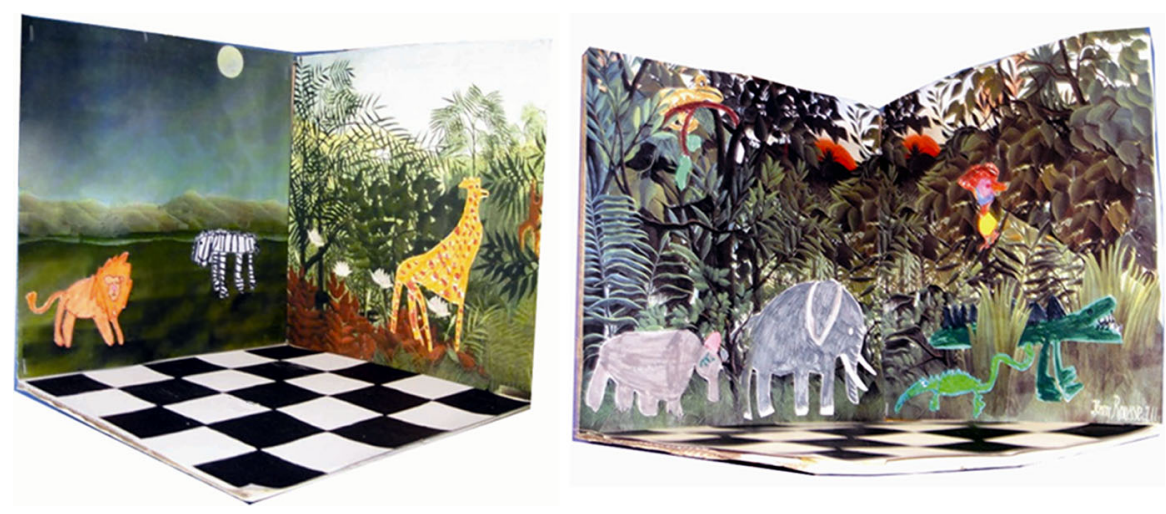

Fig. 2 In these "toy theatres" (measuring twenty centimetres in height), the animals drawn and cut out by children are applied as figures onto a background of paintings by Henry Rousseau and stood on a chessboard floor-this is an opportunity to tackle the difficulties of three-dimensional representation 

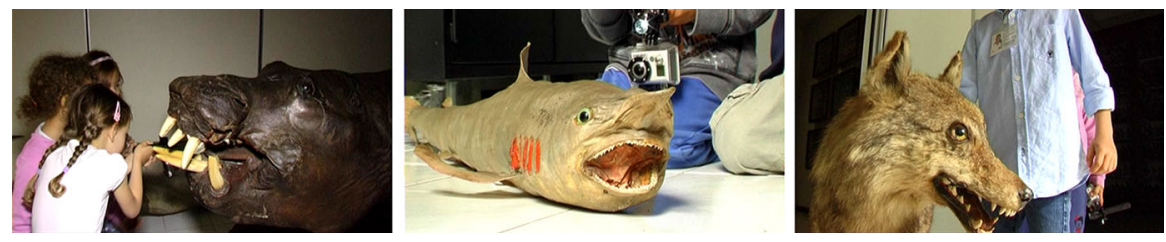

Fig. 3 Some frames from the participatory video

\section{Primary School}

Mineralogy-Two classes of 10 year old children (50 children) worked on the project, in its various forms, for about 4 months. The children began by gathering information from the Museum of Mineralogy and on the web about the figure of Torquato Taramelli (1843-1922), a leading geologist to whom the oldest secondary school in the city is dedicated. This was followed by a discussion on minerals and how they occur in nature, also considering the specimens brought in by children. The classes also visited the Museum of Mineralogy, where they observed several types of crystals and minerals. They were then taken to a laboratory with many polarised light microscopes where they observed several thin sections of different rocks (Fig. 4). In a subsequent session they were guided round a recently opened research laboratory, where they could see various advanced techniques for analysing minerals.

As a result, additions have been made to the curricula of several subjects, such as geometry and history of art (Fig. 5). A knowledge of crystals has promoted the study of some classical regular solids such as the cube, tetrahedron and octahedron. Each child drew, cut out and recomposed the various figures. They then identified and described other solid figures that are present in the real world.

Some solid figures are fundamental to figurative art, from the pyramid in Raphael (1483-1520) to the cylinder, sphere and cone in Cézanne (1839-1906), and Picasso's cubism.

In the thin sections laboratory the children commented on the iridescent beauty of the microscopic images and some pointed out that they were remarkably similar to paintings they had seen at school (Fig. 6). These were mainly works by some of the most important international figures in material and informal art-J. Pollock
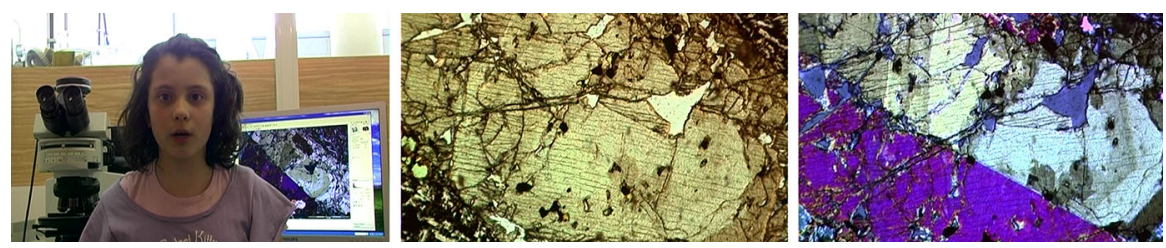

Fig. 4 A thin section is a sheet of rock cut so thin $(0.03 \mathrm{~mm})$ as to enable light to pass through most of its constituent minerals. Observed through a polarizing microscope, different colours can be seen depending on the constituent minerals. It can also reveal different colours or different shades when the stage is rotated 


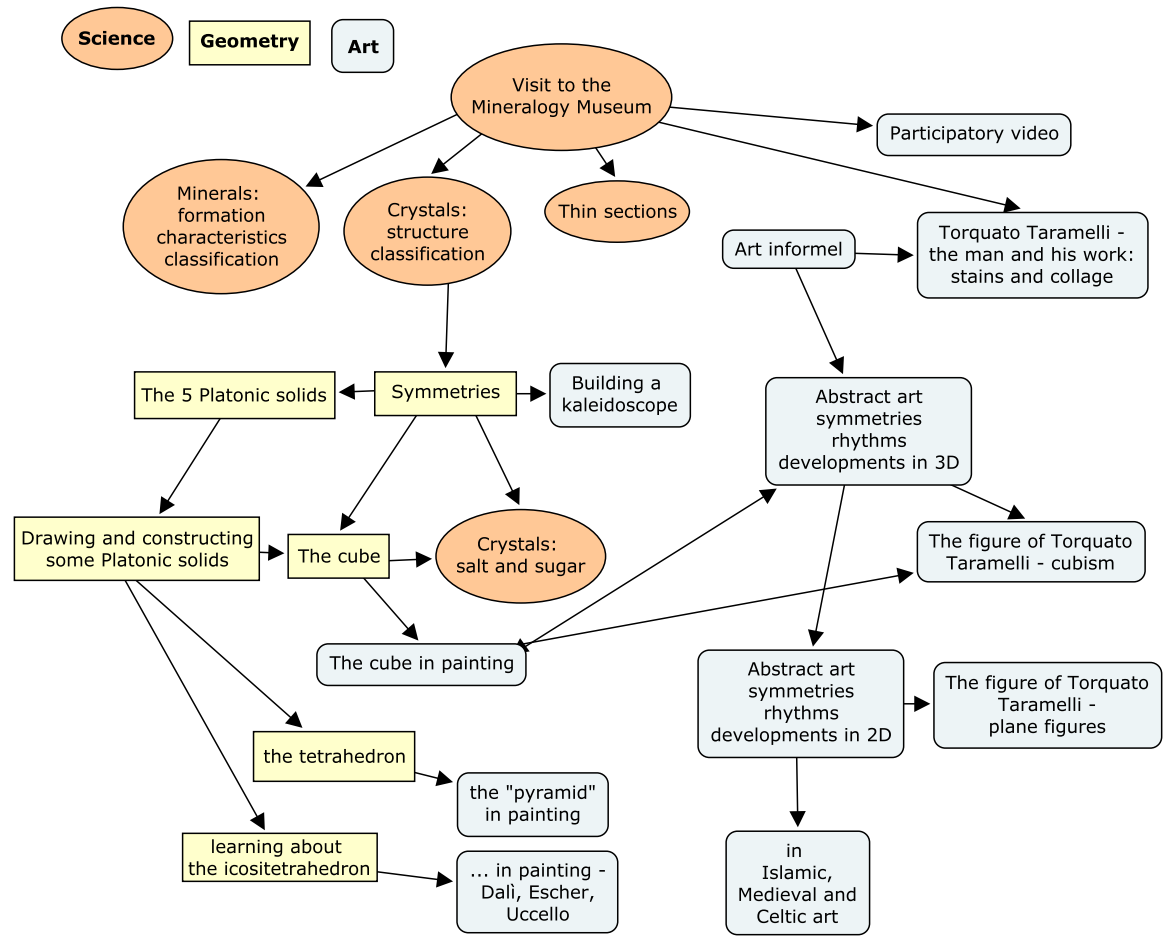

Fig. 5 Interdisciplinary exchanges: flat, solid geometrical figures are an area common to many areas of research and study, not only of a scientific nature; this allows connections between different disciplines and facilitates the preparation of interdisciplinary projects and educational pathways, involving both very different materials and activities

(1912-1956), J. Dubuffet (1901-1985), A. Burri (1915-1995) and W. Kandinskywho the students already knew. Comparing these artists and the images produced from thin sections later generated totally unexpected connections, evocations and ideas!

The creative workshops involved another range of activities, based on geometry: the teacher paused to reflect on Cubism with the children, who then began to draw a portrait of Taramelli in Cubist form "in the style of Picasso" (Fig. 7). Two types of analogy were used here: the analogy between natural and geometric forms and the analogy with the Cubism of Braque (1882-1963) and Picasso.

Other activities included finding analogies between the thin sections and abstract art: children drew thin sections "in the style of Kandinsky" on a 10 metre long roll of paper, and rocky ground on a $5 \mathrm{~m}$ long roll. The last activity was designed to "imitate" nature and the magical randomness of rocks and stones (Fig. 8). They produced drawings by spontaneously and randomly mixing colours and marks on a sheet, and finally cut these drawings into stone shapes.

Botanic Garden-Children from different classes, all aged 10, visited the university's Botanic Garden. After the visit they also took part in a workshop on the 

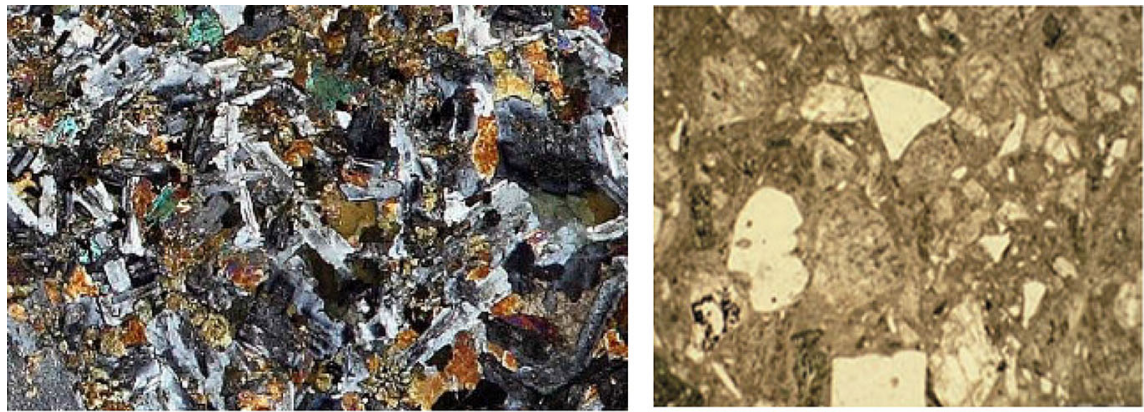

Thin section of a Dolerite

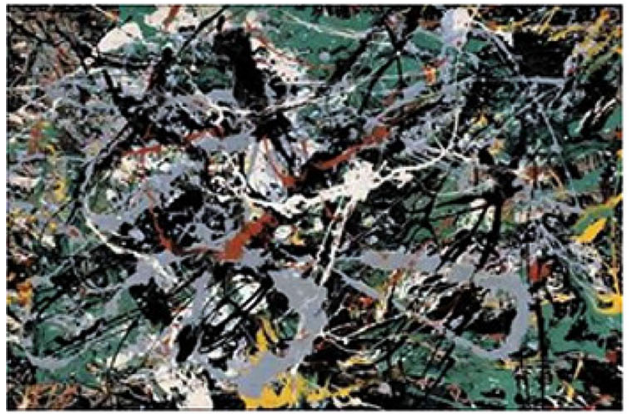

Thin section of a Trentino Porphyry

Untitled (Green Silver) - Pollok, 1949

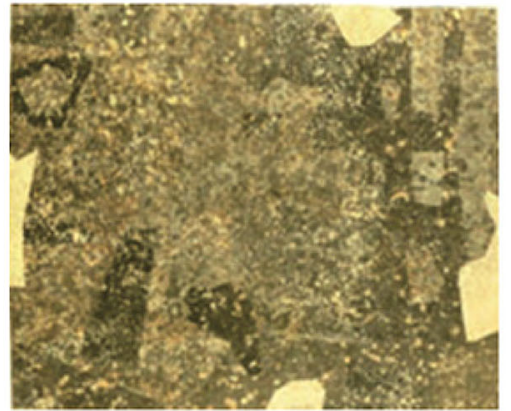

Topographie rougeâtre - Dubuffet, 1858

Fig. 6 Thin sections and works of art

Fig. 7 Translating the features of Taramelli's face into essential lines and volumes requires a keen eye and detailed knowledge of the Cubist style

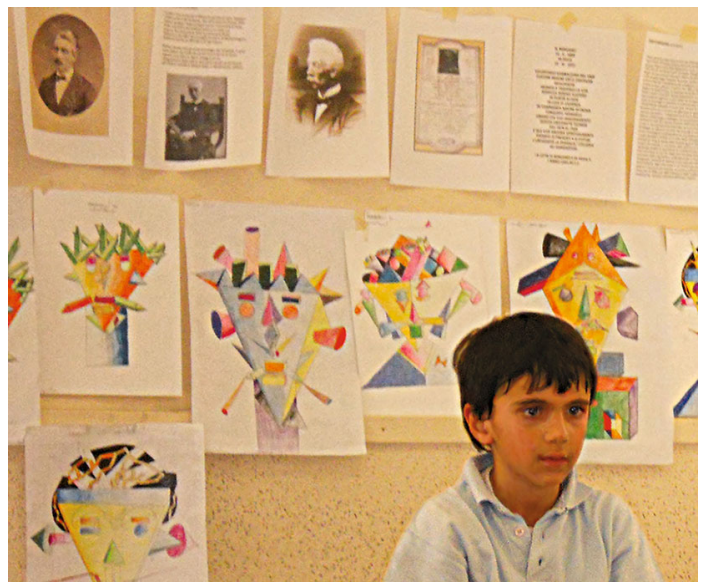

morphology of leaves and bark and on the reproduction of plants. The topics discussed during the visit and the workshop were then explored at school, alongside the traditional science curriculum. Children were particularly interested in the problem of plant nutrition and the function of soil. Humus and its composition aroused great curiosity (Figs. 9, 10). 


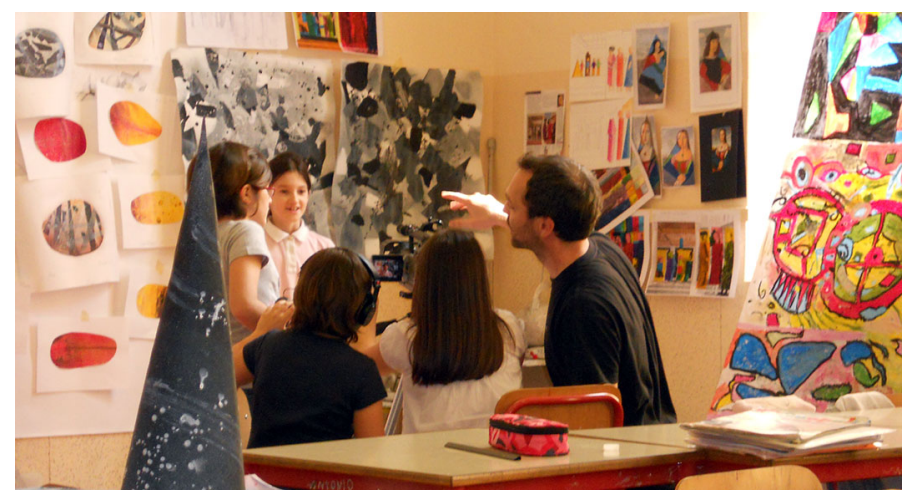

Fig. 8 Drawing stones means imitating nature, and playing in a carefree, though not disorderly manner

Comparing the barks of different trees led to identifying their different rhythms and geometries. The children began by making rubbings directly from the bark, then identified their essential lines and used geometric rigour to translate them onto graph paper. The geometric forms identified in the barks of different trees, were then creatively reinterpreted and used (Fig. 11) as textures for clothing and everyday objects (cars, furniture and furnishings).

Three $6 \mathrm{~m}$ long drawings were made, using different techniques superimposed at random, in a repeated pattern, drawing leaves and insects of different sizes that were continuously superimposed. After completing it the children brushed it with several layers of coffee. The drawing thus turned into one large picture with a uniform tone (Fig. 12). In this case the analogy evokes the layers of leaves in the underbrush which, as they continue to fall, help to produce humus.

Participatory video - A participatory video was produced by two of the classes that visited the Botanic Gardens and the History of Pavia University Museum (Fig. 13). The children took on the roles of director, sound technician and actor.
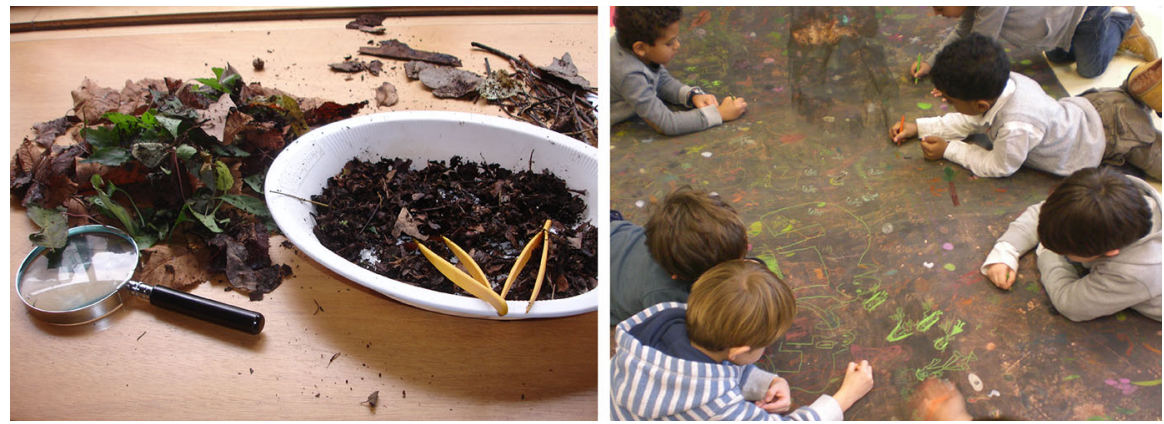

Fig. 9 Workshop on humus at the Botanic Garden. Creative workshop: six metres of painted surface (acrylic colours) with different shades of earth mixed and superimposed, imitate the texture of humus and contain an infinite number of minor additions of plant, animal and mineral origin (chalks and colour pencils). Inspired in particular by the painting of J. Dubuffet 


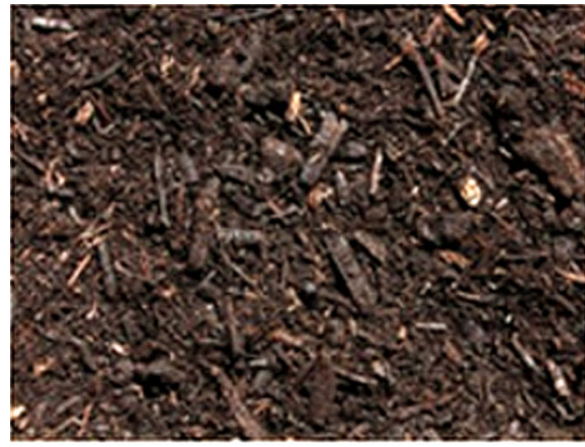

Humus

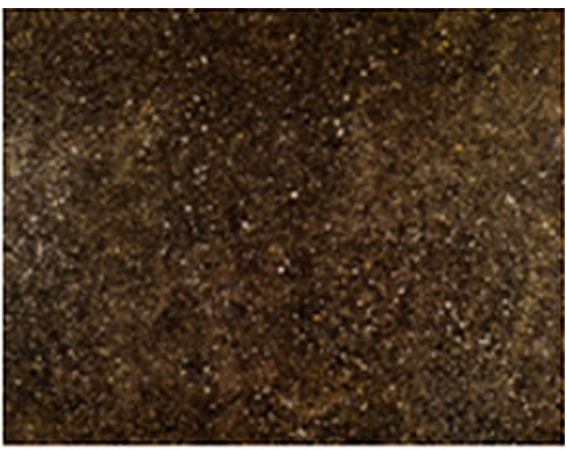

Fruits de feu du sol Dubuffet, 1959

Fig. 10 J. Dubuffet's informal painting "imitates" the randomness of nature. Some of its surfaces have the same irregularity as undergrowth, bare earth and fertile humus. The artist follows the poetics of "art brut", rejecting rules of composition and imitation while making use of gesture and the sensuality of the materials of which things are made

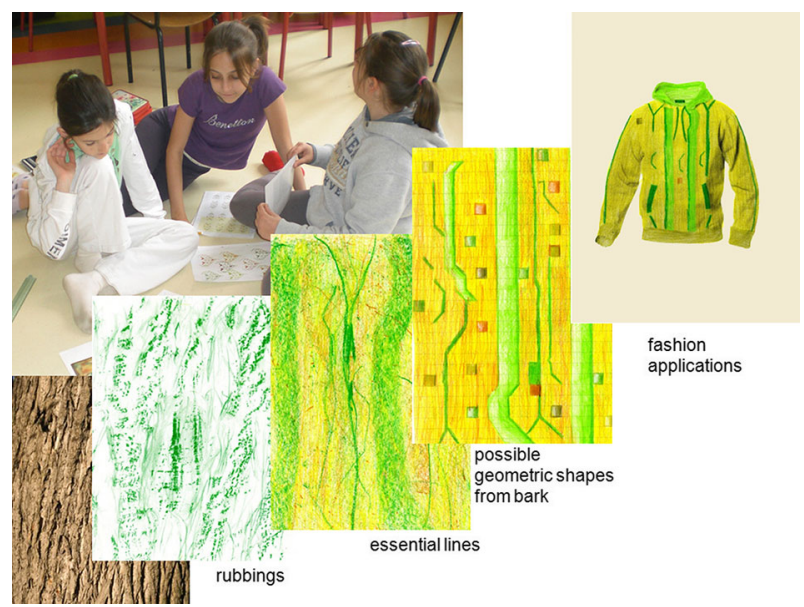

Fig. 11 Bark lines, reproduced by means of rubbings, and transformed into geometric shapes can be used for fabrics and decorations

The aptitudes and roles were based on the preferences of each pupil and the talents identified through some games ${ }^{5}$ in a session before shooting began. During the session, the children were given the chance to try out the video and audio recording equipment.

\footnotetext{
${ }^{5}$ Different games were used depending on the children's age and the roles they chose. The youngest imitated animals and their movements while others shot scenes with a videocamera; the oldest told true or invented stories that their companions tried to recognise, shot scenes and tested the steadiness of their hands through games of dexterity.
} 

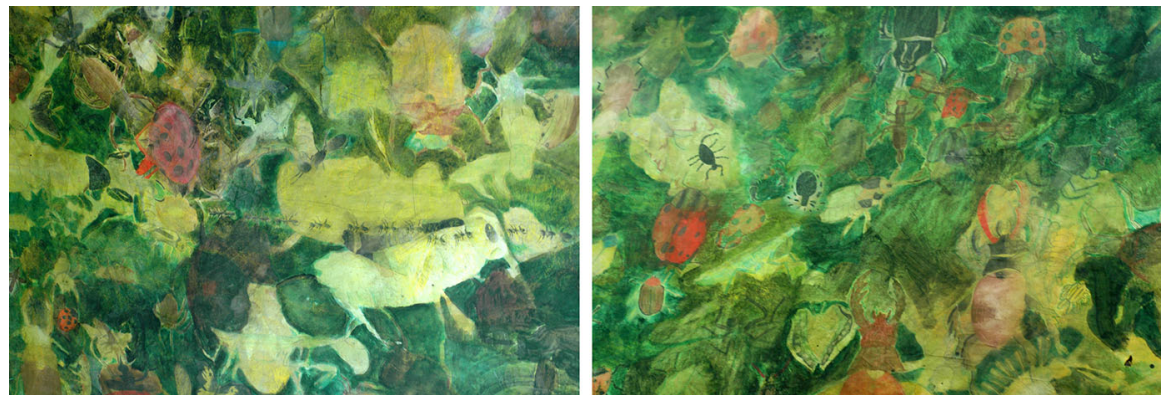

Fig. 12 Insects, drawn in superimposed layers. Parts of the design
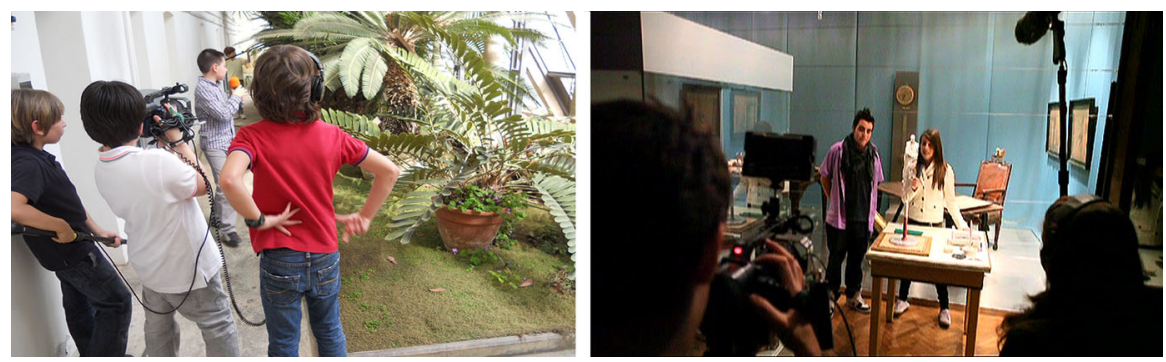

Fig. 13 Children during shooting at the Botanic Garden and at the History of Pavia University Museum

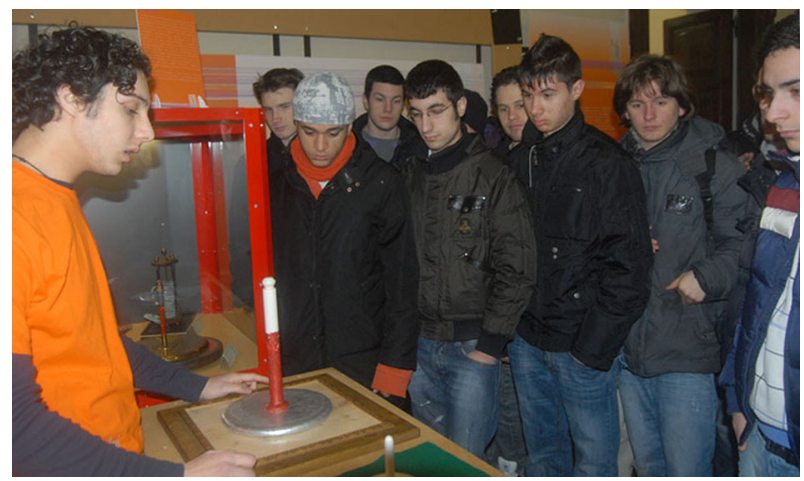

Fig. 14 A secondary school student explains to a visiting class how Volta's electrophorus and pile work

\section{Secondary School Pupils}

Pupils showed the historical experiments to their peers, to elementary school children, and to visitors of the exhibition (Fig. 14).

Some classes chose a scientist and produced videos in which they narrated a story (Figs. 15, 16, 17). The subject of the story was chosen by the group and the 

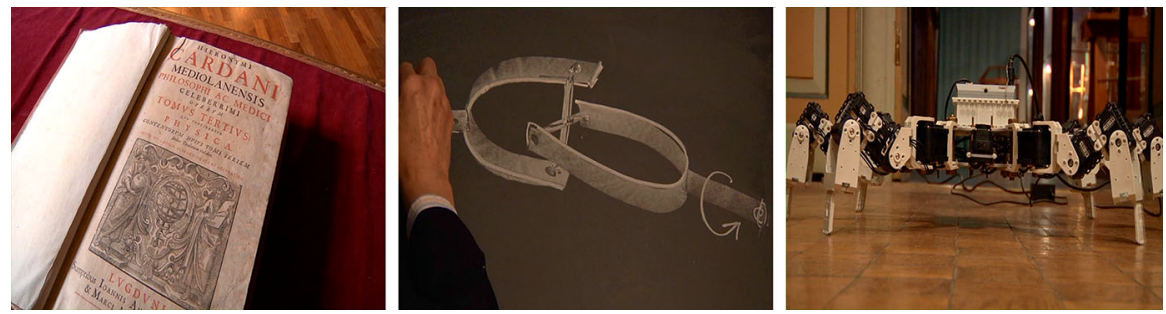

Fig. 15 The scientist chosen by a technical school was Gerolamo Cardano. The pupils and their teacher also created a robot, in which two of Cardano's discoveries - the cardan shaft and the solution of cubic equations-played an important role
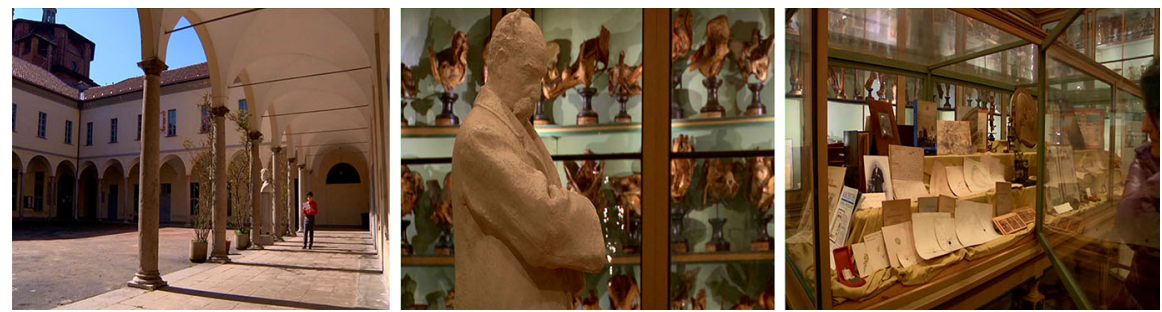

Fig. 16 Pupils of a classics lyceum chose the scientist Camillo Golgi, who studied at their school in the nineteenth century. They drew inspiration from a particular episode in the political and social context of Golgi's life, an episode in which they found some similarities with their particular stage in school life
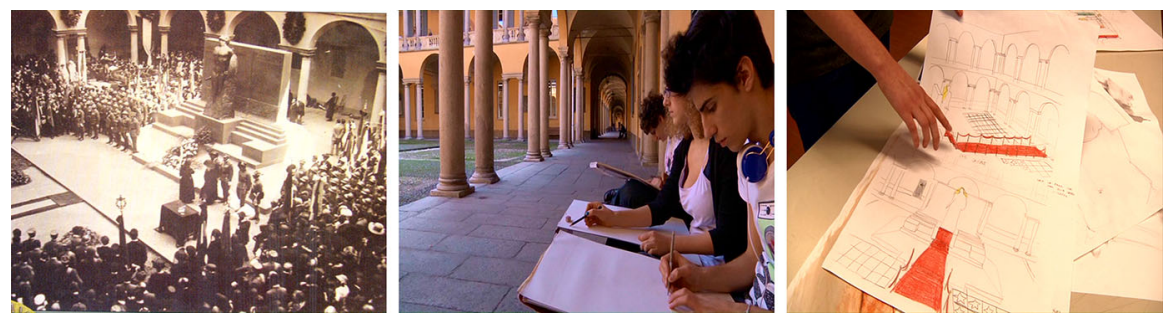

Fig. 17 In the case of an arts lyceum, the protagonists of the story were the professors and university students who died in the First World War. The university courtyard dedicated to them was the site of the installations created by the school kids

storyboard was also written by the group. The results are science stories, told by pupils, which sometimes also take into account the social and political contexts in which the scientists lived.

Some videos produced by schools, as well as a number of those produced by about two hundred and fifty undergraduate students studying communication, innovation and multimedia, formed part of an augmented reality project. The purpose of this project was to provide information about our university, its most illustrious figures and their inventions and discoveries. We used QR codes to 


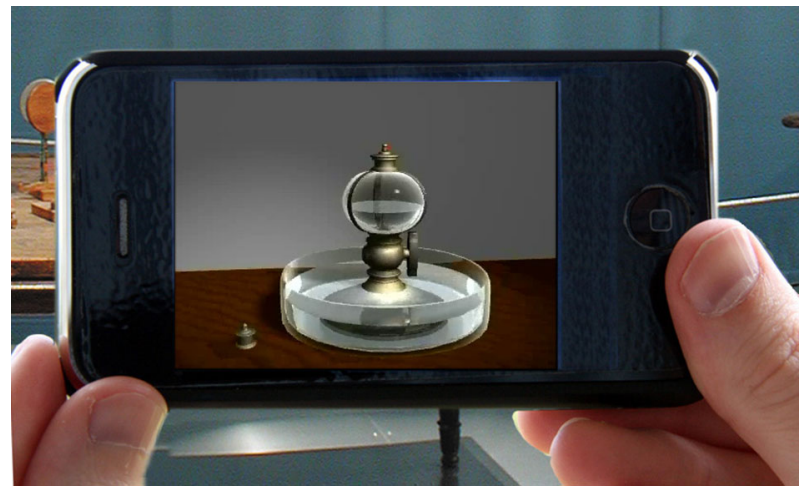

Fig. 18 A QR linked to a 3D animation produced by our group. The smartphone reads the QR code linked to Volta's eudiometer, which plays a clip explaining how it works

communicate the information, as they are inexpensive and can be read by any smartphone. As a result, the courtyards, lecture rooms and university museums were dotted with "tiny squares" linking up to explanatory texts, to past images of one's location, to video clips made by the History of Science group (Fig. 18), as well as to videos and pictures produced by all those participating in the Neverland project. We hope to extend the augmented reality project in the near future to the city, which is rich in history.

Open Access This article is distributed under the terms of the Creative Commons Attribution License which permits any use, distribution, and reproduction in any medium, provided the original author(s) and the source are credited.

\section{References}

Andreani, L., Bevilacqua, F., Cardinali, L., Falomo Bernarduzzi, L., Marabelli, F., \& Mascheretti, P. (2010). Energia, questa trasformista. Pavia: La Goliardica Pavese.

Bevilacqua, F., \& Bordoni, S. (2005). Electromagnetic induction: symmetries and interpretations. In J. Renn (Ed.), Albert Einstein, chief engineer of the universe. One hundred authors for Einstein (pp. 60-63). Weinheim: Wiley-VCH.

Bevilacqua, F., \& Falomo Bernarduzzi, L. (2009). Classical electromagnetic theory: Textbooks, history, stories and web 2.0. In P. Kokkotas \& F. Bevilacqua (Eds.), Professional development of science teachers: Teaching science using case studies from the history of science (pp. 51-80). Seattle: Amazon-CreateSpace.

Bevilacqua, F., Falomo Bernarduzzi, L., Fregonese, L., Giannetto, E., Giudice, F. S., \& Mascheretti, P. (2006). The pendulum: From constrained fall to the concept of potential. Science \& Education, 15(6), 553-575.

Bevilacqua, F., Falomo Bernarduzzi, L., \& Garbarino, M. C. (Eds.). (2003). Musei e collezioni dell'Università di Pavia. Milano: Casa Editrice Ulrico Hoepli.

Bruner, J. (1986). Actual minds, possible worlds. Cambridge, MA: Harvard University Press.

Bruner, J. (1996). The culture of education. Cambridge, MA: Harvard University Press.

Bruner, J. S., Jolly, A., \& Sylva, K. (Eds.). (1976). Play. Its role in development and evolution. New York: Basic Books.

De Bartolomeis, F. (1990). Girare intorno all'arte. Valutare e produrre. Scandicci: La Nuova Italia. 
Eshach, H. (2007). Bridging in-school and out-of-school learning: Formal, non-formal, and informal education. Journal of Science Education and Technology, 16(2), 171-190.

Falomo Bernarduzzi, L., Albanesi, G., \& Bevilacqua, F. (2012). Museum heroes all: The Pavia approach to school-science museum interactions. Science \& Education, doi:10.1007/s11191-012-9541-x. ISSN: 0926-7220.

Gardner, H. (1983). Frames of mind. The theory of multiple intelligences. New York: Basic Books Inc.

Gombrich, E. H. (1979). The sense of order. A study in the psychology of decorative art. Oxford: Phaidon Press.

Heering, P. (2000). Getting shocks: Teaching secondary school physics through history. Science \& Education, 9(4), 363-373.

Hodkinson, P., Colley, H., \& Malcom, J. (2003). The Interrelationships between informal and formal learning. Journal of Workplace Learning, 15(7/8), 313-318.

Jonassen, D. H., Howland, J., Marra, R. M., \& Crismond, D. P. (2008). Meaningful learning with technology (3rd ed.). Upper Saddle River, NJ: Pearson/Merrill Prentice Hall.

Kanizsa, G. (1980). Grammatica del vedere. Saggi su percezione e gestalt. Bologna: Il Mulino.

Kisiel, J. F. (2005). Understanding elementary teacher motivations for science field trips. Science \& Education, 89(6), 936-955.

Laporte, P. M. (1966). Cubism and Relativity with a letter of Albert Einstein. Art Journal, 25(3), 246-248.

Macchietti, S. (1997). Giocare nella scuola, il gioco nella scuola materna. Firenze: IRRSAE/Ministero della Pubblica Istruzione.

Ministero dell'Istruzione, dell'Università e della Ricerca. (2012). Indicazioni nazionali per il curricolo della scuola dell'infanzia e del primo ciclo d'istruzione, D.M. 254 del 16 novembre 2012 in G.U. n. 30 del 5 febbraio 2013. Retrieved from http://www.indicazioninazionali.it/documenti_Indicazioni_ nazionali/DM_254_201_GU.pdf.

Oliverio, A., \& Oliverio Ferraris, A. (2005). Le età della mente. Milano: Bur. RCS.

Piaget, J. (1923). Le langage et la pensée chez l'enfant. Paris: Delachaux et Niestlé.

Piaget, J., \& avec la collaboration de Garcia, R. (1971). Les explications causales. Paris: Presses universitaires de France.

Pichon-Rivière, E. (1987). El proceso creador. Buenos Aires: ed. Nueva Visión.

Singer, D. G., \& Singer, J. L. (1990). The house of make-believe: Children's play and the developing imagination. Cambridge, MA: Harvard University Press.

Stinner, A., McMillan, B. A., Metz, D., Jilek, J. M., \& Klassen, S. (2003). The renewal of case studies in science education. Science \& Education, 12(7), 617-643.

Vecchiato, M. (2007). Il gioco psicomotorio. Roma: Armando Editore.

Vygotskji, L. S. (1990). Pensiero e linguaggio. Ricerche psicologiche. Roma-Bari: Laterza.

Wallon, H. (1963). Les origines de la pensée chez l'enfant. Paris: Presses universitaires de France. 